University of Warwick institutional repository: http://go.warwick.ac.uk/wrap

This paper is made available online in accordance with publisher policies.

Please scroll down to view the document itself. Please refer to the repository record for this item and our policy information available from the repository home page for further information.

To see the final version of this paper please visit the publisher's website. Access to the published version may require a subscription.

Author(s): Kandala N-B, C Ji , N Stallard, S Stranges \& FP Cappuccio Article Title: Morbidity from diarrhoea, cough and fever among young children in Nigeria Year of publication: 2008

Link to published version:

http://www.ingentaconnect.com/content/maney/atmp/2008/00000102/00000005/art00006 


\title{
Morbidity from diarrhoea, cough and fever among young children in Nigeria
}

\author{
N.-B. KANDALA ${ }^{\star}$, C. JI ${ }^{\star}$, N. STALLARD ${ }^{\dagger}$, S. STRANGES ${ }^{\star}$ and F. P. CAPPUCCIO ${ }^{\star}$ \\ ${ }^{\star}$ Clinical Sciences Research Institute, Warwick Medical School, University of Warwick, Clifford \\ Bridge Road, Coventry CV2 2DX, U.K. \\ ${ }^{\dagger}$ Health Sciences Research Institute, Warwick Medical School, University of Warwick, Coventry \\ CV4 7AL, U.K.
}

Received 5 November 2007, Revised 27 December 2007, Accepted 2 Fanuary 2008

\begin{abstract}
Diarrhoea, cough and fever are the leading causes of childhood morbidity and mortality in sub-Saharan Africa. Despite it being a determinant of mortality in many developing countries, geographical location has seldom been considered as an explanatory factor for the large regional variations seen in the childhood morbidity attributed to these causes in this area. The relevant data collected in two Nigerian Demographic and Health Surveys, one in 1999 and the other in 2003, have now therefore been analysed and compared. The aim was to reveal and explore inequalities in the health of Nigerian children by mapping the spatial distribution of childhood morbidity associated with recent diarrhoea, cough and fever and accounting for important risk factors, using a Bayesian geo-additive model based on Markov-chain-Monte-Carlo techniques.

Although the overall prevalences of recent diarrhoea, cough and fever recorded in 1999 (among children aged $<3$ years) were similar to those seen in 2003 (among children aged $<5$ years), the mapping of residual spatial effects indicated that, in each survey, the morbidity attributable to each of these causes varied, differently, at state level. Place of birth (hospital $v$. other), type of feeding (breastfed only $v$. other), parental education, maternal visits to antenatal clinics, household economic status, marital status of mother and place of residence were each significantly associated with the childhood morbidity investigated. In both surveys, children from urban areas were found to have a significantly lower risk of fever than their rural counterparts. Most other factors affecting diarrhoea, cough and fever differed in the two surveys. The risk of developing each of these three conditions increased in the first 6-8 months after birth but then gradually declined. The analysis explained a significant share of the pronounced residual spatial effects. Maps showing the prevalences of diarrhoea, cough and fever in young children across Nigeria were generated during this study. Such maps should facilitate the development of policies to fulfil the Millennium Development Goals in Nigeria and throughout sub-Saharan Africa.
\end{abstract}

Diarrhoea, cough and fever are the leading causes of childhood morbidity and mortality in sub-Saharan Africa (SSA). According to the World Health Organization (WHO, 1996), each child in this region has a mean of five episodes of diarrhoea/year, and 800,000 children/year die from diarrhoea and dehydration. In 2005 the most populous country in this region, Nigeria, had an annual birth rate of about $4.1 \%$ offset by

Reprint requests to: N.-B. Kandala.

E-mail: n-b.kandala@warwick.ac.uk; fax: +44(0)247 6968660 . a mortality 'rate', among children aged $<5$ years, of $19.7 \%$ (www.unicef.org/ infobycountry/nigeria.html).

In many of their attempts to improve public health, health planners depend on healthcare interventions that are based on a correct understanding of the diseases that affect childhood morbidity. General sanitary conditions, mother's education and place of residence are already known to be strongly associated with childhood morbidity in SSA (Yohannes et al., 1992). In addition, the child's age, the quality and quantity of water available, the availability of toilet facilities, 
household size, feeding practices, environmental conditions and economic status of households also have a significant impact on diarrhoea and respiratory diseases among the young children who live in this region (Woldemicael, 2001).

The aim of the present study was to investigate geographical effects on morbidity among young children in Nigeria, by analysing the relevant data collected in two Nigerian demographic and health surveys (NDHS). Detailed information on the geographical distribution of childhood morbidity should help policy-makers to direct their intervention plans more effectively.

\section{MATERIALS AND METHODS}

\section{Data}

Data were collected from the 1999 and 2003 NDHS. Each of these surveys included questions designed to explore child survival and health and socio-economic and environmental conditions at household level. All the information was collected from female interviewees aged 15-49 years. In each survey, the health status of each interviewee's 'young' children (i.e. children aged $\leqslant 35$ months in the 1999 survey and children aged $\leqslant 59$ months in the 2003 survey) was assessed by asking the interviewee 'Has your child had diarrhoea, cough and/or fever in the last 2 weeks?'. Overall, data on 3552 and 6029 'young' children were collected in the 1999 and 2003 surveys, respectively.

In the analysis of the survey results, many of the factors investigated were re-categorized to be comparable with the results of previous studies. A mother's marital status, for example, was re-categorized as either 'single' or 'married', and household size was re-categorized as 'small' (if there were fewer than six members), 'medium' (if there were six to 10 members) or 'large' (if there were at least 11 members). On the basis of answers to appropriate questions, the way in which a child was fed was recorded as 'exclusively breastfed', 'not breastfed' or 'mixed feeding', and assets indices were generated, as indicators of the economic status of each study household.

For administrative purposes, Nigeria is subdivided into regions and states. Although the regional division changed between the 1999 and 2003 surveys (with only five regions making up the country in 1999 but six regions in 2003), there were the same 37 states at the time of both surveys. For the present study, prevalences of diarrhoea, cough and fever among the young children were determined both at regional and state level. Geo-additive Bayesian modelling, with dynamic and spatial effects, was then used to assess temporal and geographical variation in these three conditions. The model used also allows for the non-linear effects of covariates to be investigated (see below).

\section{Statistical Methods}

In the analysis of survey data, the commonly adopted models are probit or logistic, and the standard measure of effects is the odds ratio (Yohannes et al., 1992; Woldemicael, 2001). In the present study, however, the geographical nature of the data and the presence of non-linear effects for some covariates meant that strictly linear predictors could not be assumed. In a novel approach (see Appendix), the regional patterns of childhood morbidity and the possibly non-linear effects of other factors were therefore explored within a simultaneous, coherent regression framework, using a geo-additive, semi-parametric, mixed model (Fahrmeir and Lang, 2001; Kandala and Madise, 2004; Brezger et al., 2005; Kandala, 2006). In brief, the strictly linear predictor:

$$
\eta_{i}=x_{i}^{\prime} \beta+w_{i}^{\prime} \gamma
$$

is replaced with a logit link function with dynamic and spatial effects, $\operatorname{Pr}\left(y_{i}=1 \mid \eta_{i}\right)=\mathrm{e}^{\eta i} /\left(1+\mathrm{e}^{\eta i}\right)$, and a geoadditive semi-parametric predictor $\mu_{\mathrm{i}}=\mathrm{h}\left(\eta_{i}\right)$ :

$$
\begin{aligned}
\eta_{i}= & f_{1}\left(x_{i 1}\right)+\ldots+f_{p}\left(x_{i p}\right) \\
& +f_{\text {spat }}\left(s_{i}\right)+w_{i}^{\prime} \gamma
\end{aligned}
$$


where $h$ is a known response function with a logit link function, $f_{1}, \ldots, f_{p}$ are non-linear smooth effects of the metrical covariates (child's and mother's age), and $f_{\text {spat }}\left(s_{i}\right)$ is the effect of the spatial covariate $s_{i}\{1, \ldots, S\}$ labelling the Nigerian state. Covariates in $w_{i}{ }^{\prime}$ are categorical variables such as gender and urban-rural residence. Regression models with predictors such as those in Equation 2 are sometimes referred to as geo-additive models. P-spline priors were assigned to the functions $f_{1}, \ldots, f_{p}$, while a Markov random field prior was used for $f_{\text {spat }}\left(s_{i}\right)$ (Fahrmeir and Lang, 2001; Kandala and Madise, 2004; Brezger et al., 2005; Kandala, 2006). Although the estimation process with this model is complex, the estimated posterior odds ratios (OR) that were produced should be interpreted as those of ordinary logistic models.

The analysis was carried out using version 0.9 of the BayesX software package (Brezger et al., 2005), which permits Bayesian inference based on Markov-chain-Monte-Carlo (MCMC) simulation techniques. The statistical significances of apparent associations between potential risk factors and the prevalences of recent diarrhoea, cough and fever were explored in $\chi^{2}$ and Mann-Whitney $U$ tests, as appropriate. Multivariate analysis was used to evaluate the significance of the posterior OR determined for the fixed, nonlinear effects and spatial effects. A $P$-value of $<0.05$ was considered indicative of a statistically significant difference.

\section{RESULTS}

The data from the 1999 survey included 3121 valid observations for diarrhoea, 3098 for cough and 3119 for fever in 'young' children. In the 2003 survey (with its broader definition, by age, of a 'young' child), there were 5068 valid observations for diarrhoea, 5054 for cough and 5046 for fever.

In the descriptive analysis, two pairs of frequency tables were generated - one pair to show the prevalences of diarrhoea, cough and fever in 1999 and 2003, split by state and region (Tables 1 and 2), and the other to show the corresponding prevalences split by potential risk factor (Tables 3 and 4).

Despite the slight change in the age definition of a 'young' child between the two surveys, the overall prevalences of diarrhoea, cough and fever recorded among the young children in 1999 (13.9\%, 20.3\% and $27.5 \%$, respectively) were not significantly different from the corresponding values recorded in $2003(15.4 \%, 20.2 \%$ and $26.6 \%$, respectively). These national prevalences and the aggregated regional prevalences concealed, however, important spatial variation in the childhood morbidity recorded at state level (see Table 1). In the South East region in 1999, for example, the overall prevalence of diarrhoea among the young children investigated was $15.0 \%$ but the corresponding state-level prevalences varied from $9.5 \%$ (in Enugu) to $28.6 \%$ (in Bayelsa).

Certain regions were associated with relatively high prevalences of diarrhoea, cough and/or fever. In 1999 (Table 1), for example, diarrhoea was relatively common among the young children from the North West $(P<0.001)$ and Central $(P<0.001)$ regions, whereas cough was positively associated with the North West $(P<0.001)$, South East $(P=0.031)$, South West $(P<0.001)$ and Central $(P<0.001)$ regions, and fever was positively associated with the North East $(P=0.002)$, North West $(P<0.001)$, South West $(P<0.001)$ and Central $(P=0.006)$ regions. In 2003 (Table 2), the North Central $(P<0.001)$, North East $(P<0.040)$ and North West $(P<0.001)$ regions were each positively associated with diarrhoea, cough and fever, the South East with diarrhoea only $(P=0.004)$, the South South with both cough $(P=0.001)$ and fever $(P=0.007)$, and the South West with both diarrhoea $(P<0.001)$ and fever $(P=0.026)$.

Tables 3 and 4 show the prevalences of diarrhoea, cough and fever for all fixed categorical factors and the relationship, if 
any, between each factor and prevalence children: in 1999 these were hospital deliv(not accounting for any spatial effects) in ery, exclusive breastfeeding, an educated 1999 and 2003. Several factors appeared to mother and an educated mother's partner reduce the risk of diarrhoea in young whereas in 2003 they were urban residence,

TABLE 1. The prevalences of recent diarrhoea, cough and fever (i.e. that occurring within the previous 2 weeks) among young children in each Nigerian state in 1999, as reported in the Demographic and Health Survey in that year

\begin{tabular}{|c|c|c|c|c|c|c|c|}
\hline Region & State & $\begin{array}{l}\% \text { of children with } \\
\text { recent diarrhoea and } \\
\text { (no. investigated) }\end{array}$ & \% & $\begin{array}{l}\% \text { of children with } \\
\text { recent cough and } \\
\text { (no. investigated) }\end{array}$ & 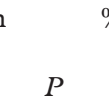 & $\begin{array}{l}\% \text { of children with } \\
\text { recent fever and } \\
\text { (no. investigated) }\end{array}$ & 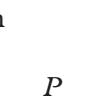 \\
\hline \multirow{7}{*}{ North East } & Bauchi & $23.2(125)$ & & $27.2(125)$ & & $34.4(125)$ & \\
\hline & Borno & $15.9(63)$ & & $22.2(63)$ & & $27.4(62)$ & \\
\hline & Kano & $28.3(258)$ & & $20.6(257)$ & & $44.0(259)$ & \\
\hline & Jigawa & $19.8(81)$ & & $20.0(80)$ & & $22.5(80)$ & \\
\hline & Yobe & $17.2(99)$ & & $27.3(99)$ & & $38.4(99)$ & \\
\hline & Gombe & $23.1(39)$ & & $17.5(40)$ & & $22.5(40)$ & \\
\hline & All six & $23.2(665)$ & 0.14 & $22.7(664)$ & 0.52 & $35.9(665)$ & 0.002 \\
\hline \multicolumn{2}{|c|}{ North WestKaduna } & $29.8(131)$ & & $28.1(128)$ & & $53.8(132)$ & \\
\hline & Katsina & $17.4(184)$ & & $12.5(184)$ & & $27.9(183)$ & \\
\hline & Sokoto & $6.3(80)$ & & $8.8(80)$ & & $17.5(80)$ & \\
\hline & Kebbi & $12.7(79)$ & & $26.0(77)$ & & $28.2(78)$ & \\
\hline & Zamfara & $19.3(119)$ & & $20.5(117)$ & & $35.3(119)$ & \\
\hline & All five & $18.4(593)$ & $<0.001$ & $18.8(586)$ & $<0.001$ & $33.8(592)$ & $<0.001$ \\
\hline \multirow[t]{10}{*}{ South East } & Akwa Ibom & $15.8(171)$ & & $36.5(170)$ & & $46.8(173)$ & \\
\hline & Anambra & $9.7(62)$ & & $33.9(62)$ & & $30.6(62)$ & \\
\hline & Cross River & $17.3(52)$ & & $30.8(52)$ & & $40.4(52)$ & \\
\hline & Imo & $14.8(61)$ & & $52.5(61)$ & & $49.2(61)$ & \\
\hline & Rivers & $17.3(52)$ & & $32.0(50)$ & & $40.4(52)$ & \\
\hline & Abia & $15.2(66)$ & & $26.6(64)$ & & $39.4(66)$ & \\
\hline & Enugu & $9.5(42)$ & & $21.4(42)$ & & $33.3(42)$ & \\
\hline & Bayelsa & $28.6(14)$ & & $28.6(14)$ & & $35.7(14)$ & \\
\hline & Ebonyi & $14.9(47)$ & & $23.9(46)$ & & $31.9(47)$ & \\
\hline & All nine & $15.0(567)$ & 0.77 & $33.5(561)$ & 0.03 & $40.8(569)$ & 0.28 \\
\hline \multicolumn{2}{|c|}{ South WestEdo } & $3.6(83)$ & & $32.9(79)$ & & $29.3(82)$ & \\
\hline & Lagos & $5.2(116)$ & & $28.4(116)$ & & $21.4(117)$ & \\
\hline & Ogun & $7.0(114)$ & & $7.9(114)$ & & $11.4(114)$ & \\
\hline & Ondo & $11.5(61)$ & & $23.0(61)$ & & $37.7(61)$ & \\
\hline & Oyo & $6.8(118)$ & & $11.8(119)$ & & $28.7(122)$ & \\
\hline & Delta & $14.0(93)$ & & $32.3(93)$ & & $28.0(93)$ & \\
\hline & Osun & $5.6(72)$ & & $12.5(72)$ & & $12.7(71)$ & \\
\hline & Ekiti & $0(12)$ & & $0(12)$ & & $0(12)$ & \\
\hline & All eight & $7.3(669)$ & 0.12 & $20.3(666)$ & $<0.001$ & $23.1(672)$ & $<0.001$ \\
\hline \multirow[t]{10}{*}{ Central } & Benue & $7.1(98)$ & & $19.6(97)$ & & $12.4(97)$ & \\
\hline & Adamawa & $38.6(57)$ & & $51.8(56)$ & & $37.5(56)$ & \\
\hline & Kwara & $9.2(65)$ & & $24.6(65)$ & & $18.5(65)$ & \\
\hline & Niger & $21.4(98)$ & & $25.3(95)$ & & $27.4(95)$ & \\
\hline & Plateau & $19.0(79)$ & & $19.0(79)$ & & $34.2(79)$ & \\
\hline & Kogi & $8.1(99)$ & & $9.2(98)$ & & $19.2(99)$ & \\
\hline & Taraba & $7.1(70)$ & & $21.4(70)$ & & $24.6(69)$ & \\
\hline & Nassarawa & $11.4(35)$ & & $14.3(35)$ & & $22.9(35)$ & \\
\hline & $\begin{array}{l}\text { Federal Capital } \\
\text { Territory (Abuja) }\end{array}$ & $26.9(26)$ & & $23.1(26)$ & & $34.6(26)$ & \\
\hline & All nine & $15.2(627)$ & $<0.001$ & $22.2(621)$ & $<0.001$ & $24.3(621)$ & 0.006 \\
\hline All five & & $13.9(3121)$ & & $20.3(3098)$ & & $27.5(3119)$ & \\
\hline
\end{tabular}


antenatal visits, hospital delivery, exclusive age (of the child) and a relatively old breastfeeding, an educated mother, an mother. Antenatal visits, exclusive breasteducated mother's partner, a relatively high feeding, and an educated mother appeared

TABLE 2. The prevalences of recent diarrhoea, cough and fever (i.e. that occurring within the previous 2 weeks) among young children in each Nigerian state in 2003, as reported in the Demographic and Health Survey in that year

\begin{tabular}{|c|c|c|c|c|c|c|c|}
\hline Region & State & $\begin{array}{c}\% \text { of children } \\
\text { with recent } \\
\text { diarrhoea and } \\
\text { (no. investigated) }\end{array}$ & $P$ & $\begin{array}{c}\% \text { of children } \\
\text { with recent } \\
\text { cough and } \\
\text { (no. investigated) }\end{array}$ & $P$ & $\begin{array}{c}\% \text { of children } \\
\text { with recent } \\
\text { fever and } \\
\text { (no. investigated) }\end{array}$ & $P$ \\
\hline \multirow{8}{*}{ North Central } & Benue & $14.7(238)$ & & $33.9(236)$ & & $24.2(236)$ & \\
\hline & Kwara & $4.7(85)$ & & $9.4(85)$ & & $17.6(85)$ & \\
\hline & Niger & $12.9(178)$ & & $6.8(177)$ & & $15.3(177)$ & \\
\hline & Plateau & $28.5(151)$ & & $35.8(151)$ & & $39.7(151)$ & \\
\hline & Kogi & $9.3(108)$ & & $11.0(109)$ & & $13.9(108)$ & \\
\hline & Nassarawa & $14.9(74)$ & & $28.4(74)$ & & $33.8(74)$ & \\
\hline & $\begin{array}{l}\text { Abuja (Federal } \\
\text { Capital Territory) }\end{array}$ & $27.9(43)$ & & $33.3(42)$ & & $38.1(42)$ & \\
\hline & All seven & $15.7(877)$ & $<0.001$ & $23.0(874)$ & $<0.001$ & $24.6(873)$ & $<0.001$ \\
\hline \multirow[t]{7}{*}{ North East } & Bauchi & $34.6(439)$ & & $30.1(438)$ & & $37.3(437)$ & \\
\hline & Borno & $39.4(216)$ & & $34.6(217)$ & & $26.4(216)$ & \\
\hline & Adamawa & $34.4(128)$ & & $46.9(128)$ & & $55.5(128)$ & \\
\hline & Taraba & $35.8(148)$ & & $32.7(147)$ & & $48.6(146)$ & \\
\hline & Yobe & $28.6(140)$ & & 33.8 (139) & & 37.7 (138) & \\
\hline & Gombe & $23.0(126)$ & & $25.4(126)$ & & $32.5(126)$ & \\
\hline & All six & 33.7 (1197) & 0.040 & $33.0(1195)$ & 0.006 & $38.2(1191)$ & $<0.001$ \\
\hline \multirow[t]{8}{*}{ North West } & Kaduna & $8.3(350)$ & & $14(350)$ & & $34.9(350)$ & \\
\hline & Kano & $16.7(354)$ & & $16.6(355)$ & & $41.1(353)$ & \\
\hline & Katsina & $21.8(252)$ & & $13.3(248)$ & & $26.8(250)$ & \\
\hline & Sokoto & $16.3(123)$ & & $20.3(123)$ & & $25.2(123)$ & \\
\hline & Jigawa & $23.2(151)$ & & $15.9(151)$ & & $38.4(151)$ & \\
\hline & Kebbi & $23.0(139)$ & & $14.4(139)$ & & $37.7(138)$ & \\
\hline & Zamfora & 25.2 (139) & & 33.6 (137) & & 43.8 (137) & \\
\hline & All seven & $17.6(1508)$ & $<0.001$ & $17.0(1503)$ & $<0.001$ & $35.6(1502)$ & 0.001 \\
\hline \multirow[t]{6}{*}{ South East } & Anambra & 13.3 (105) & & $24.0(104)$ & & $27.9(104)$ & \\
\hline & Imo & $4.1(98)$ & & $21.4(98)$ & & $24.5(98)$ & \\
\hline & Abia & $4.2(48)$ & & $12.5(48)$ & & $18.8(48)$ & \\
\hline & Enugu & $17.4(109)$ & & $33.6(110)$ & & $38.2(110)$ & \\
\hline & Ebonyi & $6.2(97)$ & & $26.8(97)$ & & $35.1(97)$ & \\
\hline & All five & $9.8(457)$ & 0.004 & $25.2(457)$ & 0.06 & $30.2(457)$ & 0.06 \\
\hline \multirow[t]{7}{*}{ South South } & Akwa Ibom & $11.1(72)$ & & $29.2(72)$ & & $38.9(72)$ & \\
\hline & Edo & $3.6(56)$ & & $17.5(57)$ & & $19.6(56)$ & \\
\hline & Cross River & $8.7(69)$ & & 50.7 (69) & & $40.6(69)$ & \\
\hline & Rivers & $7.3(124)$ & & $25.2(123)$ & & $32.3(124)$ & \\
\hline & Delta & $6.6(106)$ & & $31.1(106)$ & & $23.6(106)$ & \\
\hline & Bayelsa & $13.5(37)$ & & $43.2(37)$ & & $48.6(37)$ & \\
\hline & All six & $8.0(464)$ & 0.49 & $31.5(464)$ & 0.001 & $32.3(464)$ & 0.007 \\
\hline \multirow[t]{7}{*}{ South West } & Lagos & 3.7 (219) & & $19.7(218)$ & & $12.8(219)$ & \\
\hline & Ogun & $17.2(99)$ & & $22.7(97)$ & & $22.1(95)$ & \\
\hline & Ondo & $15.2(46)$ & & $21.7(46)$ & & $31.1(45)$ & \\
\hline & Oyo & $3.8(106)$ & & $14.3(105)$ & & $24.8(105)$ & \\
\hline & Osun & $6.5(46)$ & & $15.2(46)$ & & $21.7(46)$ & \\
\hline & Ekiti & $4.1(49)$ & & $20.4(49)$ & & $22.4(49)$ & \\
\hline & All six & 7.3 (565) & $<0.001$ & $19.1(561)$ & 0.68 & 19.7 (559) & 0.026 \\
\hline All six & & $15.4(5068)$ & & $20.2(5054)$ & & $26.6(5046)$ & \\
\hline
\end{tabular}




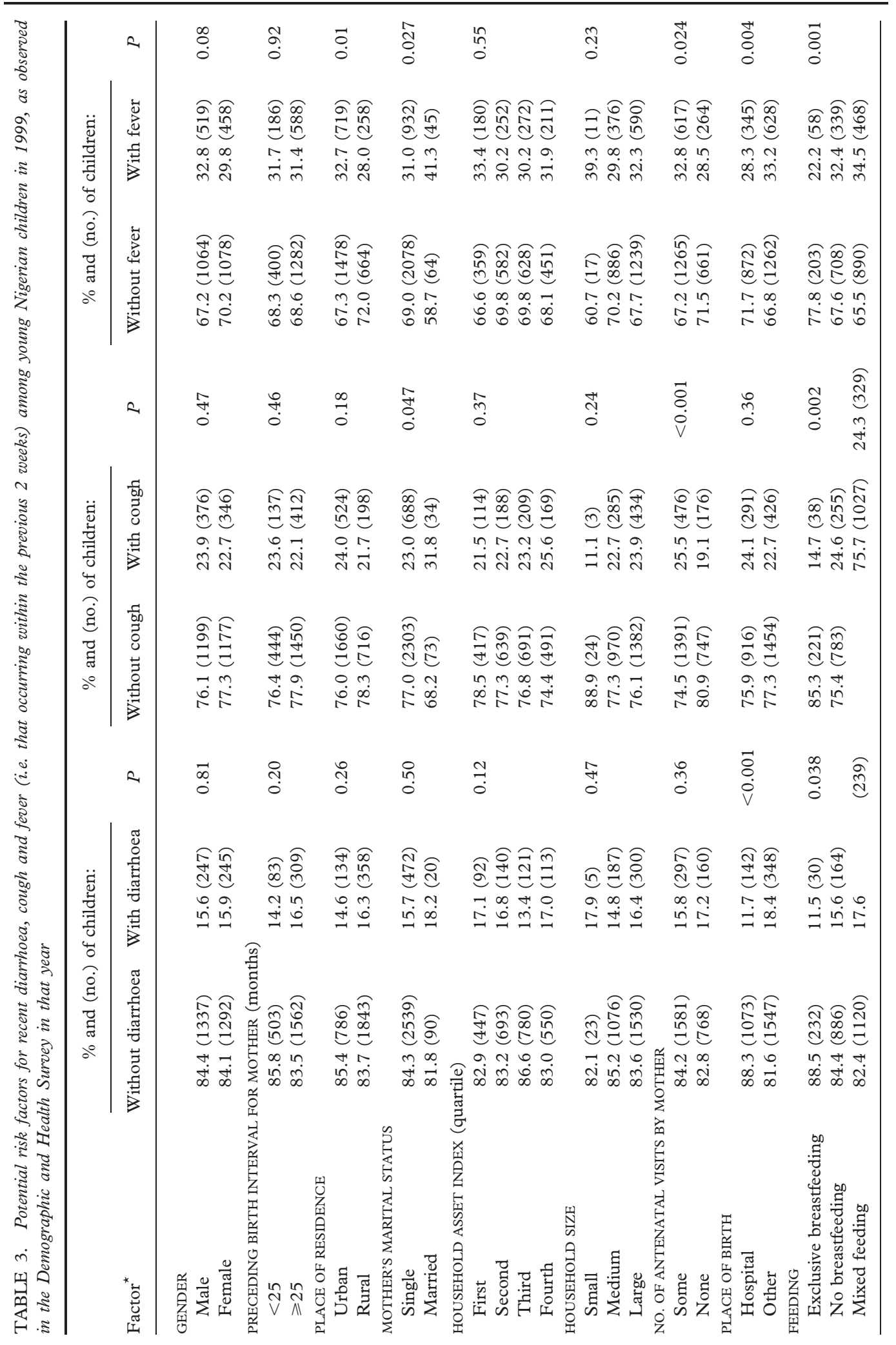




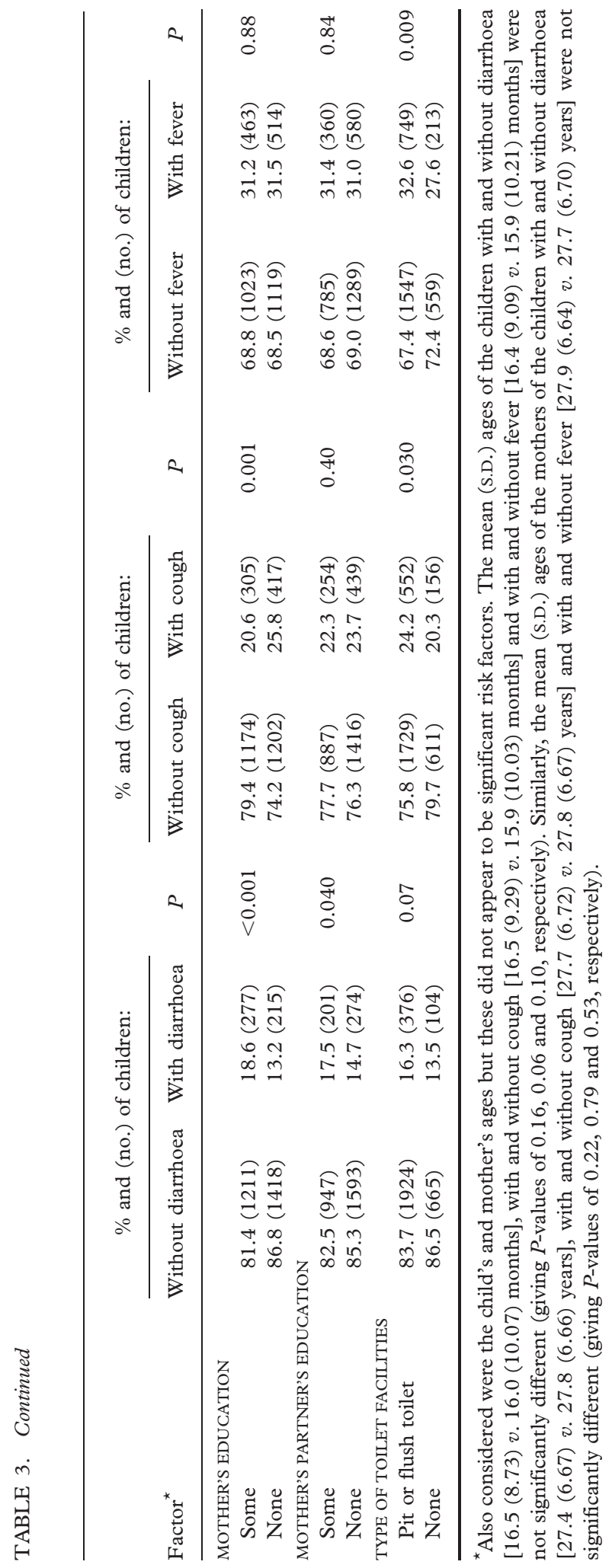




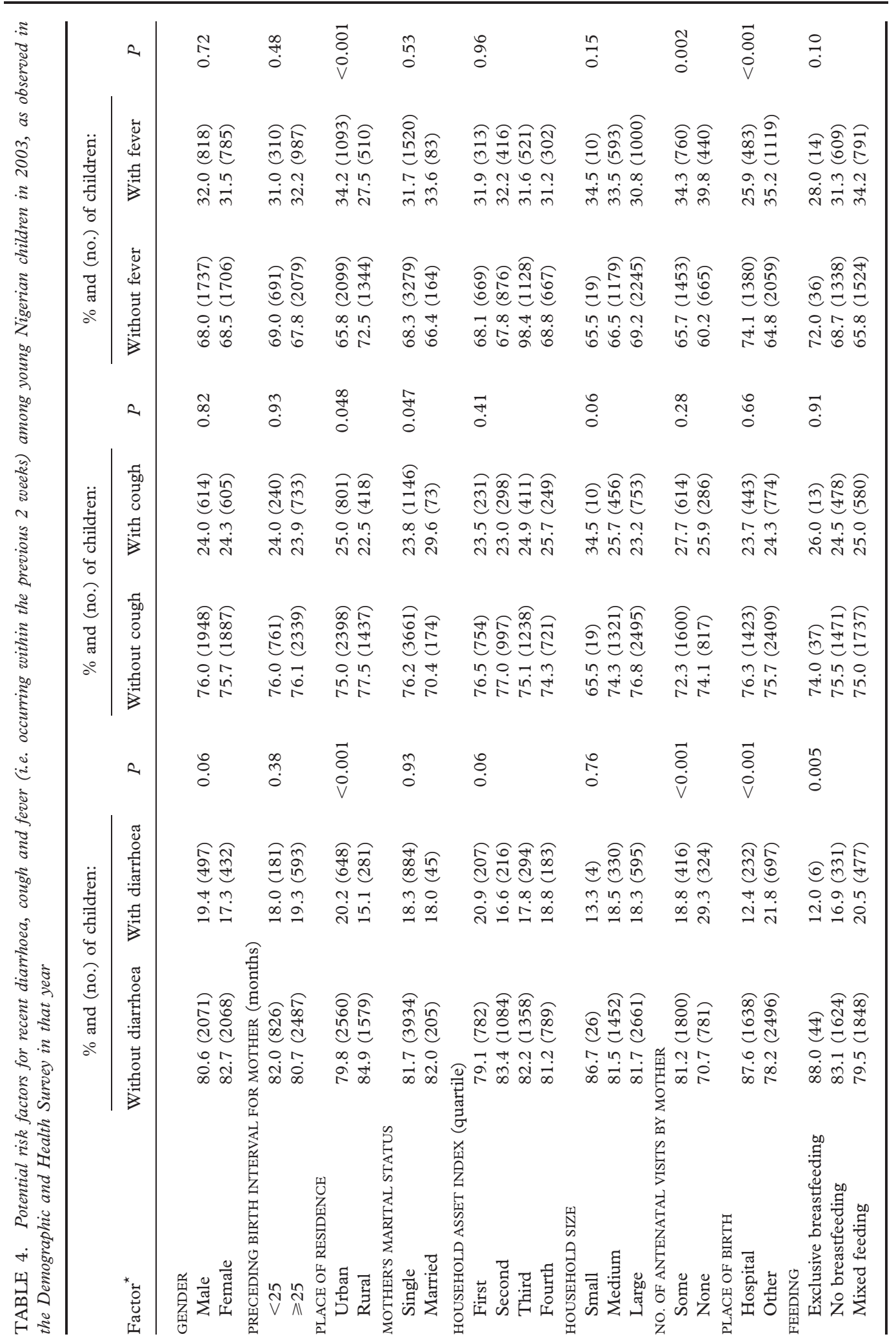




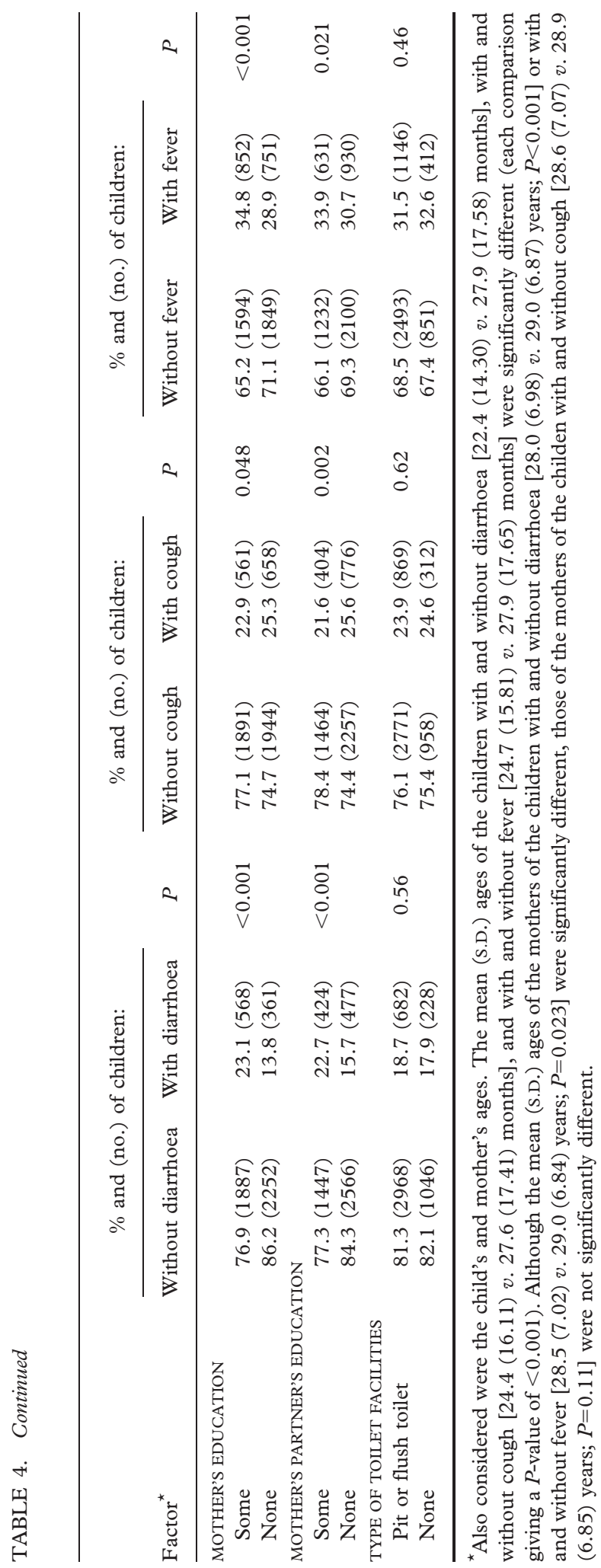




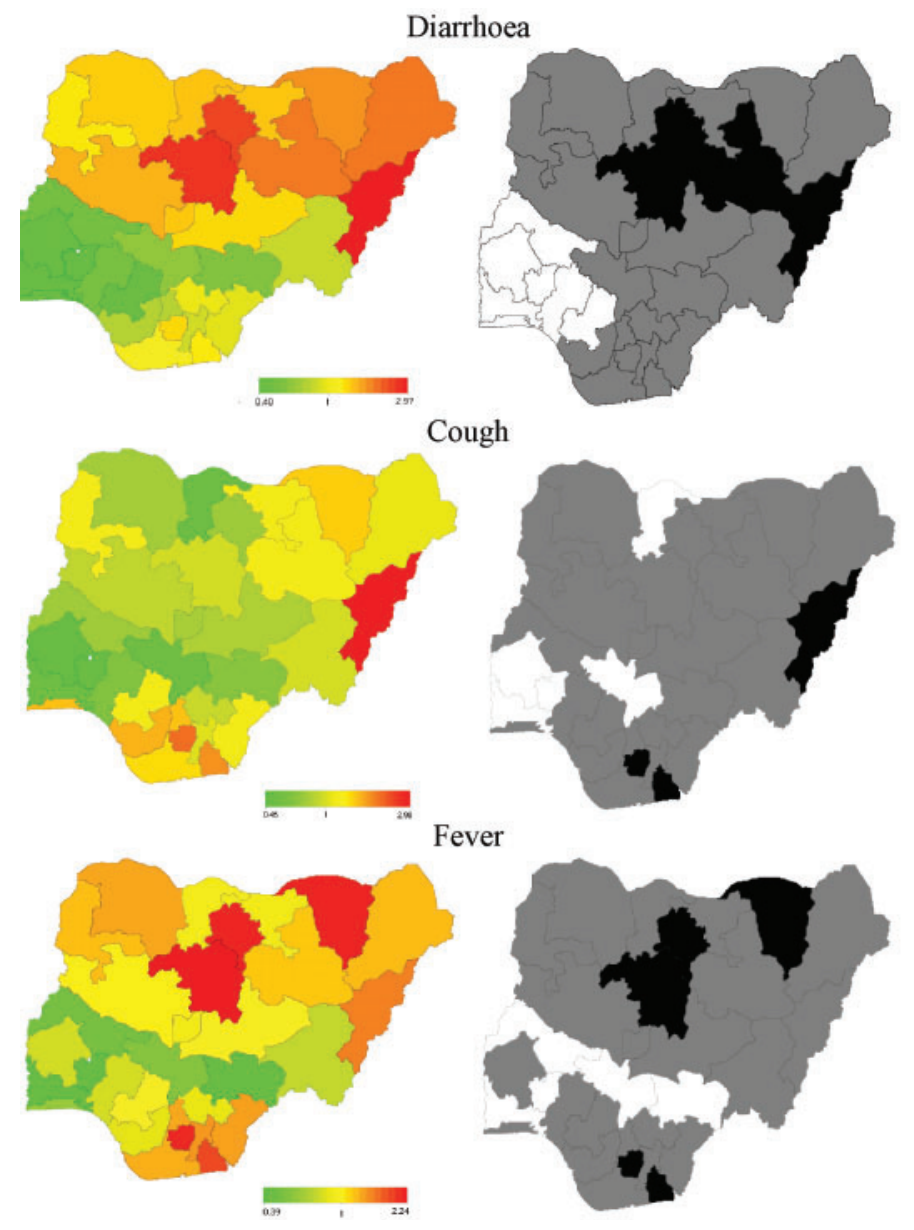

FIG. 1. Estimated odds ratios of residual spatial states effects (left) and 95\% posterior probabilities (right) of child morbidity in Nigeria in 1999. In the right-hand graphs, white indicates a negative spatial effect (associated with reduced risk of a the morbidity) and black a positive effect (and increased risk).

to reduce the risk of childhood cough in 1999 whereas only an educated mother's partner and a relatively high age appeared to have the same effect in 2003. The risks of childhood fever appeared to be reduced by urban residence, a single mother, antenatal visits, hospital delivery and exclusive breastfeeding in 1999, and by urban residence, antenatal visits, hospital delivery, an educated mother, an educated mother's partner, a relatively high age (of the child) and a relatively old mother in 2003.

In both 1999 (Fig. 1) and 2003 (Fig. 2) there was clear spatial variation in childhood diarrhoea, cough and fever in Nigeria. In
Figures 1 and 2, the left-hand maps show estimated OR for childhood diarrhoea, cough and fever in each state, with the red colour indicating the maximum OR recorded (of 2.97 for diarrhoea in 1999, 2.98 for cough in 1999, 2.24 for fever in 1999, 2.99 for diarrhoea in 2003, 2.95 for cough in 2003, and 2.30 for fever in 2003). The right-hand maps show the $95 \%$ posterior probabilities of childhood diarrhoea, cough and fever, white indicating a negative spatial effect (associated with reduced risk of the morbidity) and black a positive effect (an increased risk).

Figures 3 and 4 show the estimated nonlinear (logit) effects of the child's age and his 

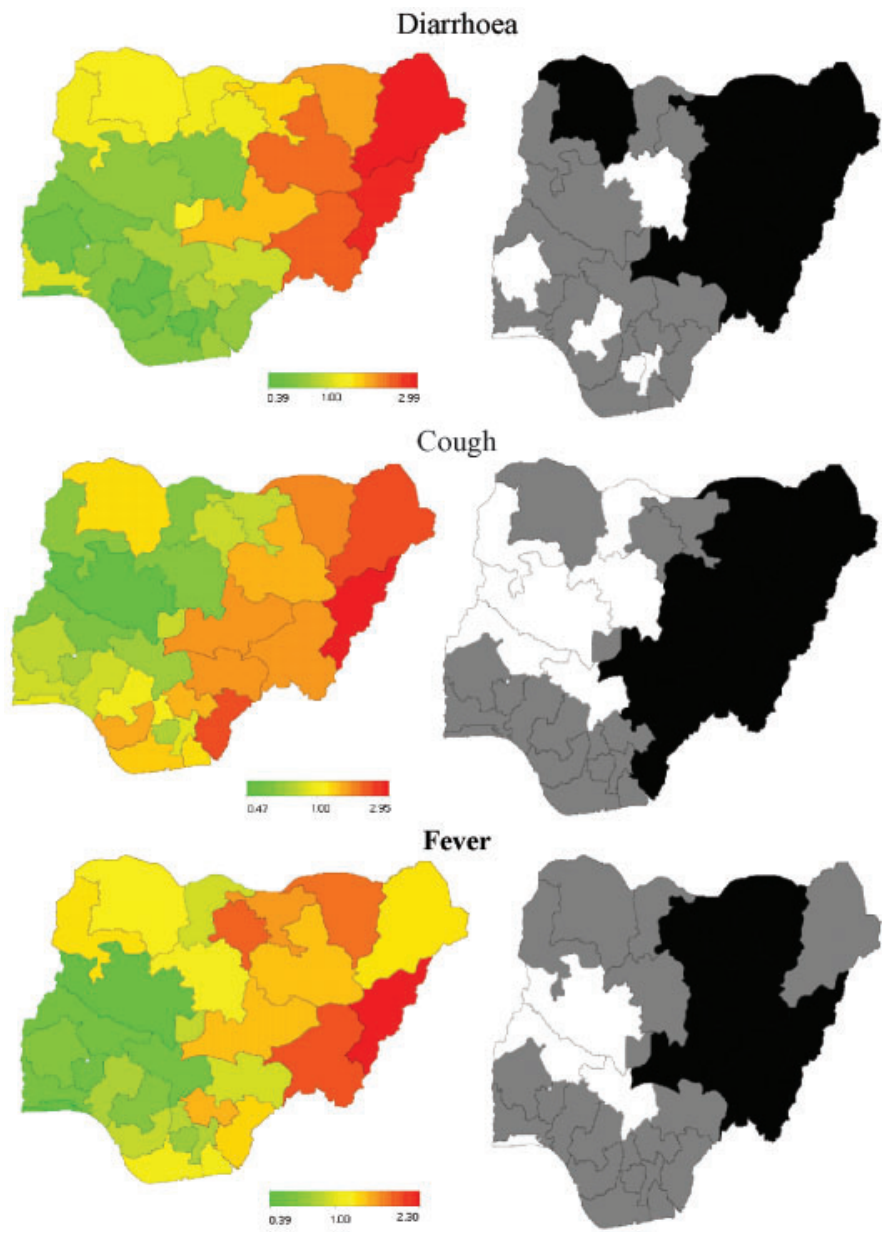

FIG. 2. Estimated odds ratios of residual spatial effects (left) and 95\% posterior probabilities (right) of child morbidity in Nigeria in 2003. In the right-hand graphs, white indicates a negative spatial effect (associated with reduced risk of a the morbidity) and black a positive effect (and increased risk).

or her mother's age on diarrhoea, cough and fever in 1999 (Fig. 3) and 2003 (Fig. 4). There appears to be a clear non-linear association between the child's age (lefthand panels) and diarrhoea, cough and fever, the graph for each type of morbidity showing a steep upward curve in the first 68 months of life (indicating that the child's health deteriorates quickly in this period). Maternal age (right-hand panels) appears to be almost linearly related with diarrhoea, cough and fever in the young child. Curiously, it appears that the younger the mother, the higher the risks of childhood diarrhoea and cough but the lower the risk of childhood fever. (In the graphs relating to maternal age, the credible intervals expand rapidly at ages of $>40$ years because of the small sample of 'older' mothers.)

The results of controlling for a range of the child's and his or her household's characteristics, to account for the fixed effects, are shown in Table 5. In 1999, children living in families in the third quintile of household economic status had a lower risk of diarrhoea $[\mathrm{OR}=0.66 ; 95 \%$ confidence interval $(\mathrm{CI})=0.46-0.94]$ than their counterparts in the first quintile. The risk of cough was lower if the mother's partner had some education $(\mathrm{OR}=0.69$; 

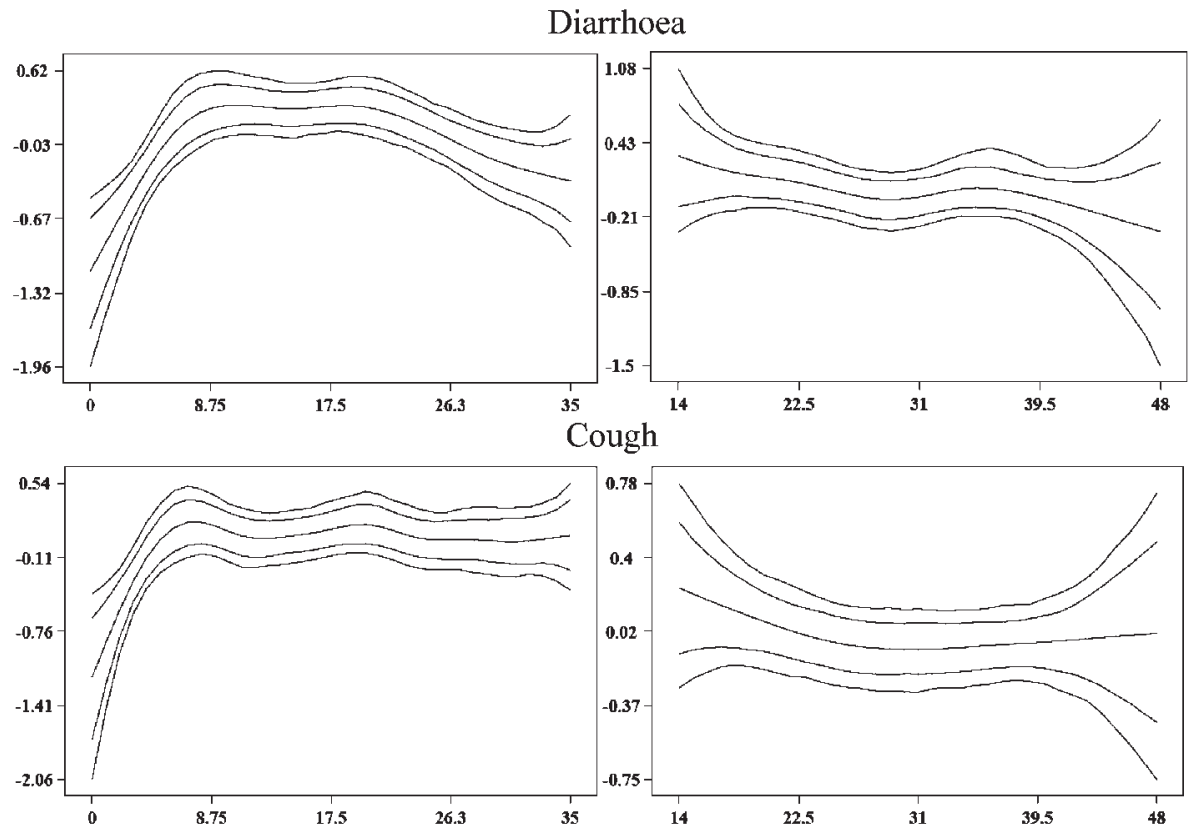

Fever
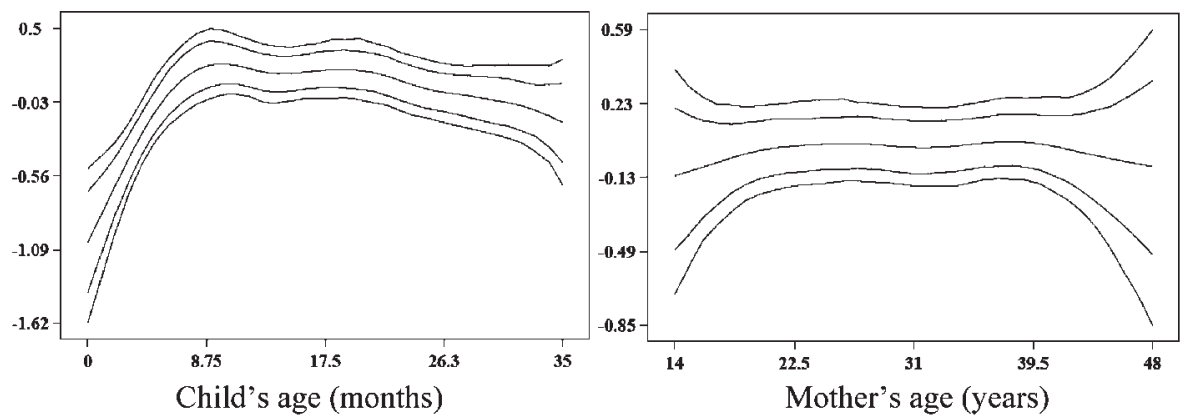

FIG. 3. Estimated non-linear (logit) effects of child's and mother's ages on the child's diarrhoea, cough and fever in 1999 , within the $95 \%$ and $80 \%$ credible intervals.

$\mathrm{CI}=0.51-0.95)$ and the mother had visited antenatal clinics $(\mathrm{OR}=0.64 ; \quad \mathrm{CI}=0.46$ 0.88 ), but living in a household in the second quintile $(\mathrm{OR}=1.40 ; \mathrm{CI}=1.20-1.98)$ or fourth quintile $(\mathrm{OR}=1.66 ; \mathrm{CI}=1.19$ 2.35), in terms of economic status, was associated with an increased risk of childhood cough. The young children of mothers who had visited antenatal clinics also had a relatively low risk of fever $(\mathrm{OR}=0.53$; $\mathrm{CI}=0.39-0.71)$. In 2003, as in 1999, the children from the 'third-quintile' families had a relatively low risk of diarrhoea
$(\mathrm{OR}=0.66 ; \quad \mathrm{CI}=0.47-0.97)$. Having an educated mother $(\mathrm{OR}=0.69 ; \mathrm{CI}=0.51$, 0.92 ) or one who had visited an antenatal clinic $(\mathrm{OR}=0.63 ; \mathrm{CI}=0.47-0.87)$ was associated with a relatively low risk of cough in 2003 but living in a household that was richer than the poorest (first) quintile increased the risk of cough (see Table 5). In 2003, the risk of childhood fever appeared to be reduced by living in an urban area $(\mathrm{OR}=0.78 ; \mathrm{CI}=0.60-0.99)$ and having a mother who had attended an antenatal clinic $(\mathrm{OR}=0.53 ; \mathrm{CI}=0.40-0.70)$. 


\section{Diarrhoea}
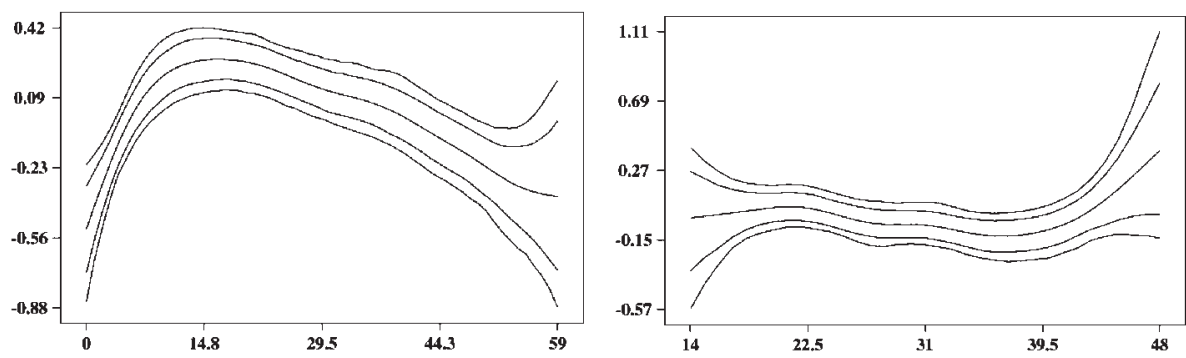

Cough
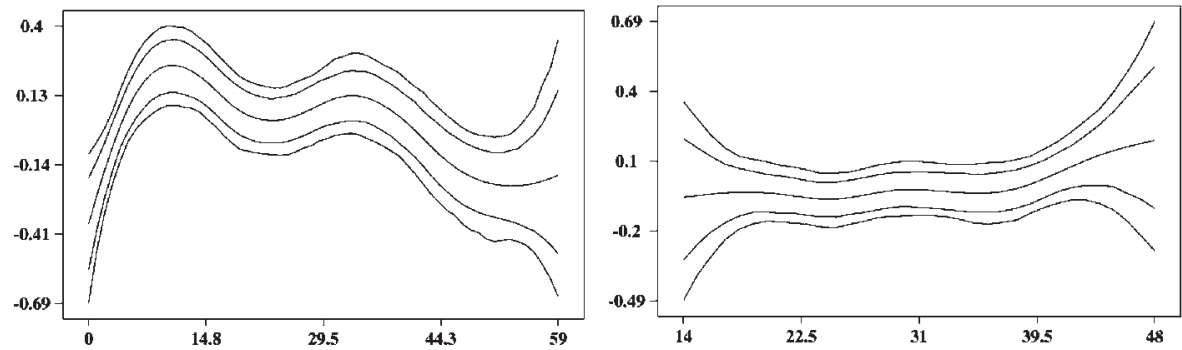

Fever
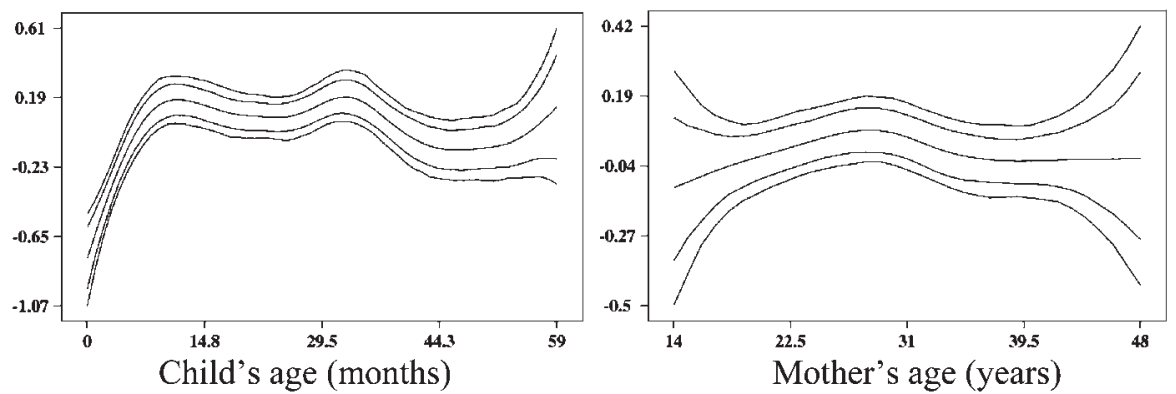

FIG. 4. Estimated non-linear (logit) effects of child's and mother's ages on the child's diarrhoea, cough and fever in 2003 , within the $95 \%$ and $80 \%$ credible intervals.

\section{DISCUSSION}

This study provides evidence of consistent and highly significant spatial variation, at state level, in the risk of childhood diarrhoea, cough and fever in Nigeria. Children from the northern and eastern states are at relatively high risk of such morbidity. The reasons for this high risk are not yet known, although climatic change and a Sahelian drought, which increased pressure on the available resources over the last few decades, may be partially responsible (Anon., 2005). In the southern states, where there is also a relatively high risk of childhood cough and fever (but not diarrhoea), some of the morbidity may be the result of the oil industry and oil spillage and the resulting environmental pollution in the Niger Delta. Oil has become a dominant part of the Nigerian economy since it was discovered in the country in the 1950s. Paradoxically, the wealth gained from this has unexpectedly led to increased degradation of the environment and deterioration in the health conditions of many local people. Gas flaring may also be a major contributing factor, with the resultant acid rain infiltrating local water sources (Anon., 2005).

The western states, where childhood morbidity is relatively rare, were used as benchmark for free education, agricultural settlements and industrial development 


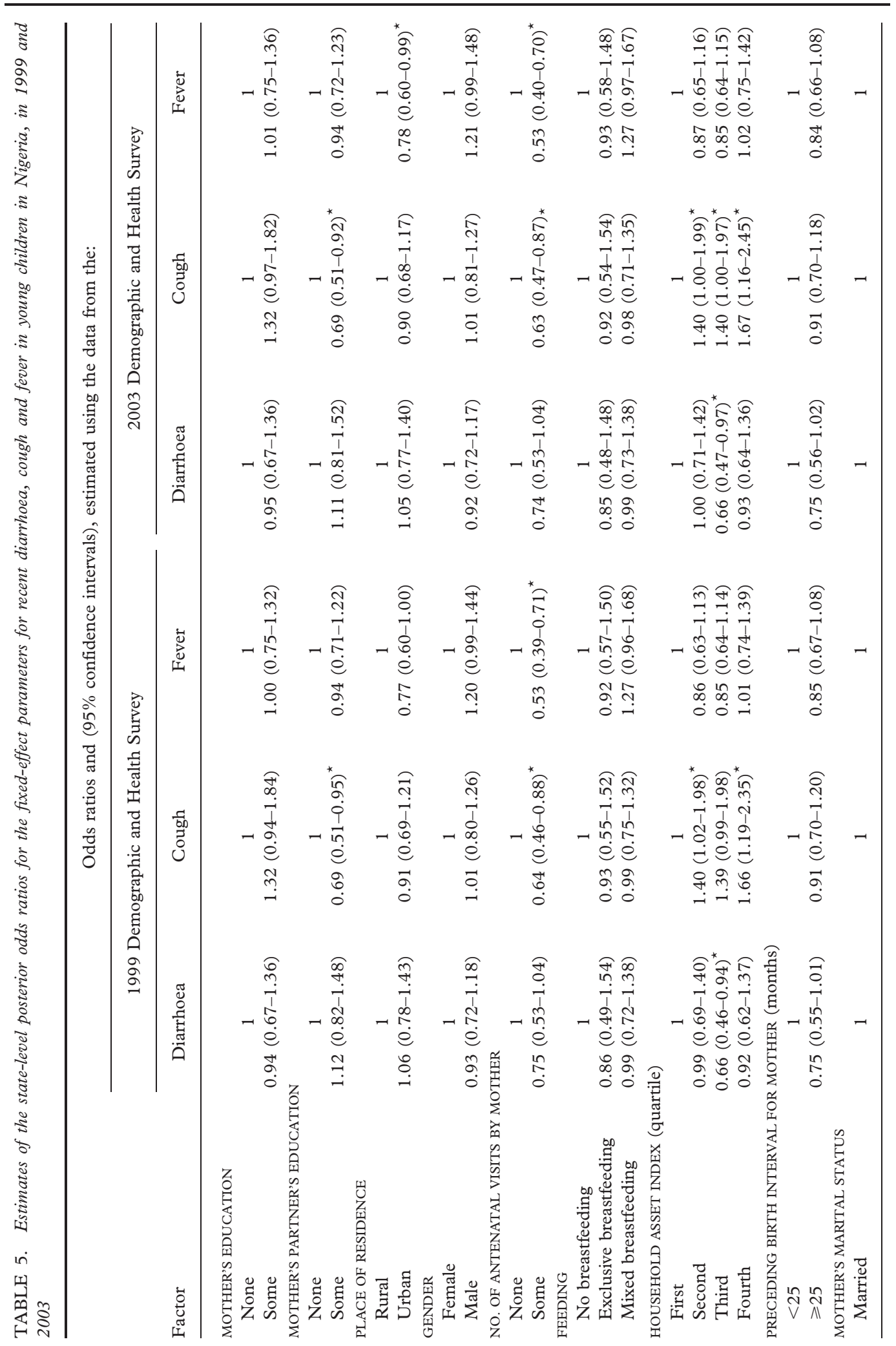




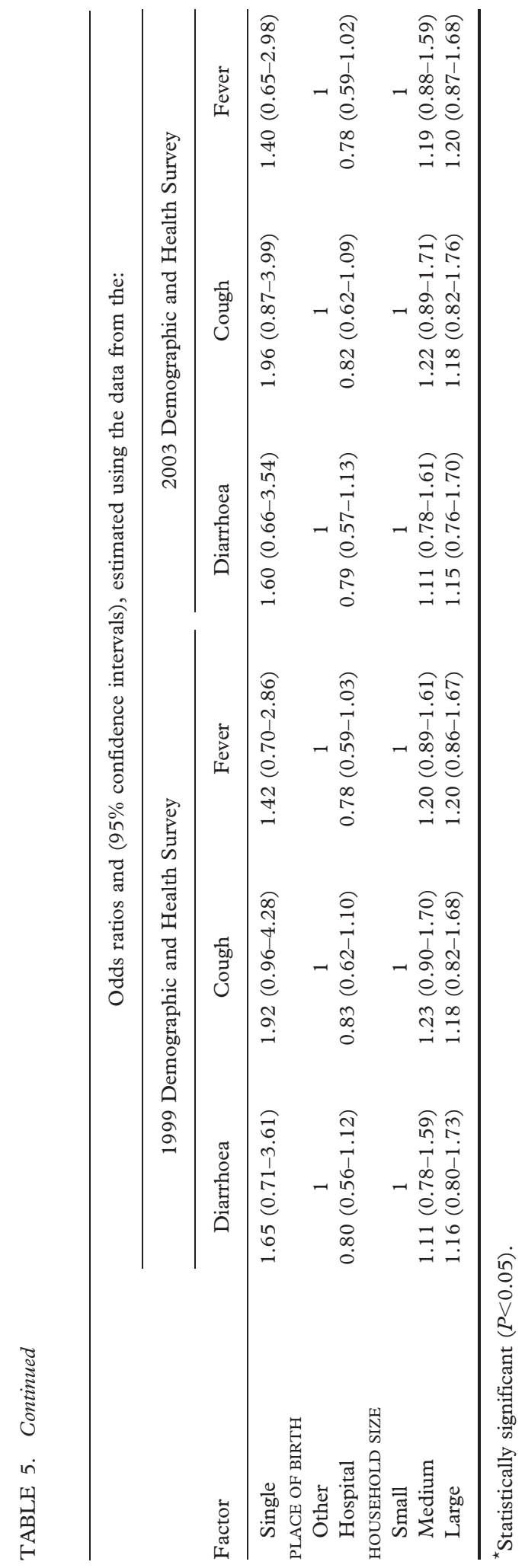


(Anon., 2006). Consequently, parents in this area are relatively well educated and likely to know more about the causes of childhood morbidity than others, hence effectively lowering the risk.

In this Nigerian study, unlike the findings from a related Kenyan investigation (Magadi, 1997), children aged 1-2 years appeared most vulnerable to diarrhoea, cough and fever. The rapid deterioration seen in the health of children in their first 8 months of life was unexpected and probably reflects the common, rapid replacement of breast milk with poor quality food and water and a general lack of immunity to the pathogens causing the morbidity (Kandala, 2006; Kandala and Ghilagaber, 2006; Kandala et al., 2006). After 8-10 months of life (when, presumably, some acquired immunity had developed), a child's age appeared to have little effect on the risk of morbidity.

Maternal age showed an almost linear, negative relationship with risk of childhood morbidity in the present study. In earlier studies, in Kenya (Magadi et al., 2000) and Malawi (Kandala et al., 2006), children born to younger mothers (aged $<20$ years) were found to have a relatively high risk of morbidity, probably because the younger mothers were much less likely to attend obstetric and antenatal clinics, where they would be educated on childcare, than their older counterparts. In the present study, in Nigeria, there was no clear and consistent relationship between the ages of the mothers and the risk of diarrhoea, cough and fever in their young children.

The results of controlling for the fixed effects indicate the importance of the mother's partner's education, residential setting (urban $v$. rural), household economic status and mother's antenatal visits on childhood morbidity. Although the education of a Nigerian mother is known to have a strong link to her healthseeking behaviour (Olaogun et al., 2006), in the present study, after controlling for spatial and non-linear effects, it was the education of the mother's partner (often the father of the young child who was studied) that was found more likely, than the education of the mother, to reduce the risk of cough in the young child. One possible explanation for this is that the role of men in African households remains dominant. An educated African man may therefore have more influence, especially on the treatment of a sick child in his household, than any female member of the household, even than the child's mother. Another plausible explanation is that, in general, an educated man is likely to have a higher socio-economic status than an uneducated one. As high socio-economic status is often associated with better sanitation and nutrition, it might also be expected to reduce some of the risks of childhood morbidity. In the present study, however, there was, surprisingly, no clear and consistent, negative correlation between socio-economic status of the household (as recorded in interviews with female householders) and risk of diarrhoea, cough and fever in the young children. In 1999, for example, children from households in the second and fourth quintiles, in terms of economic status, were more likely to have cough than their counterparts in the poorest (firstquintile) households. In 2003, however, it was the children from the poorest households who were most likely to have a recent history of cough. As expected, in 2003, children from fairly wealthy, third-quintile households had less risk of diarrhoea than children from the poorest, first-quintile households. The inconsistencies in the results for socio-economic status may reflect a major limitation in the NDHS surveys - that the socio-economic status of each study household is based on the answers to questions posed to a female member of that household (not on an independent assessment of family income, insurance, employment, assets) and therefore subject to misclassification. Another problem with the survey data, at least as far as the present study is concerned, is that the wealthiest (fourth-quintile) households produce fewer children, per household, than the second- and third-quintile households, giving a relatively small sample of young children from these wealthiest families.

Life in a rural setting appeared to be associated with fever in 2003 but not 1999 . The general advantages of urban life on a child's health in sub-Saharan Africa are well 
documented. In Nigeria, for example, children from urban areas were found to be twice as likely to be immunized and to have access to basic healthcare services as those from rural areas (Anon., 2002). In general, such advantages substantially reduce the risk of childhood morbidity.

The present analysis reveals obvious differences, in the spatial effects, between the 1999 and 2003 data-sets, with more of the northern and eastern states showing a positive spatial effect on childhood morbidity in 2003 than in 1999. With the fixed effects, important factors were consistently significant in both surveys. Some factors, such as seasonal effects and the various environmental factors associated with disease prevalence in sub-Saharan Africa, were not considered in the present study but clearly merit investigation.

Notwithstanding the limitations discussed above, the present findings give some support to those developing an integrated health policy for Nigerian children, allowing interventions to be focused on the worst affected areas and the worst affected age-groups and encouraging further attempts to improve parental education and attendance at antenatal clinics. Since there are so few modern data-sets on childhood diseases in Nigeria, it is hoped that this study will stimulate further investigation of morbidity in Nigerian children and add detail to the known spatial variation.

ACKNOWLEDGEMENTS. This research was supported financially by the United Kingdom's Economic and Social Research Council (via grant RES-000-22-1221). The authors thank J. Micklewright, for his helpful comments and discussions, Macro International, for providing free data-sets for Nigeria, and K. R. Wallbanks and two anonymous referees, for their thoughtful comments and suggestions.

\section{REFERENCES}

Anon. (2002). Child Survival in Nigeria: Situation, Response and Prospects, Key Issues. Durham, NC: Constella Futures.
Anon. (2005). Gas Flaring in Nigeria. A Human Rights, Environmental and Economic Monstrosity. Amsterdam: Climate Justice Programme, Friends of the Earth International.

Anon. (2006). Niger Delta Human Development Report. New York, NY: United Nations Development Programme.

Brezger, A., Kneib, T. \& Lang, S. (2005). BayesX: analyzing Bayesian structured additive regression models. Fournal of Statistical Software, 14, 1-22.

Fahrmeir, L. \& Lang, S. (2001). Bayesian inference for generalized additive mixed models based on Markov random field priors. Applied Statistics, 50, 201-220.

Kandala, N.-B. (2006). Bayesian geo-additive modeling of childhood morbidity in Malawi. Applied Stochastic Models in Business and Industry, 22, 139-154.

Kandala, N.-B. \& Ghilagaber, G. (2006). A geo-additive Bayesian discrete-time survival model and its application to spatial analysis of childhood mortality in Malawi. Quality and Quantity, 40, 935-957.

Kandala, N.-B. \& Madise, N. J. (2004). Spatial epidemiology of childhood diseases in Malawi and Zambia. African Population Studies, 19 (Suppl. B), 199-226.

Kandala, N.-B., Magadi, M. A. \& Madise, N. J. (2006). An investigation of district spatial variations of childhood diarrhea and fever morbidity in Malawi. Social Science and Medicine, 62, 1138-1152.

Magadi, M. A. (1997). Status of Women and Infant/child Health in Kenya with particular Reference to the High Mortality Zone in Nyanza Province. Accra: Union for African Population Studies.

Magadi, M. A., Madise, N. J. \& Rodrigues, R. N. (2000). Frequency and timing of antenatal care in Kenya: explaining the variations between women of different communities. Social Science and Medicine, 51, 551-561.

Olaogun, A. A., Adebayo, A. A., Ayandiran, O. E. \& Olasode, O. A. (2006). Effects of mother $=$ s socioeconomic status on the management of febrile conditions in their under five children in a resource limited setting. BMC International Health and Human Rights, 6, 1.

Woldemicael, G. (2001). Diarrhoea morbidity among young children in Eritrea: environmental and socioeconomic determinants. Fournal of Health, Population, and Nutrition, 19, 83-90.

World Health Organization (1996). Childhood Diseases in Africa. Fact Sheet No. 109. Geneva: WHO.

Yohannes A. G., Streatfield, K. \& Bost, L. (1992). Child morbidity patterns in Ethiopia. Fournal of Biosocial Science, 24, 143-155.

\section{APPENDIX}

Epidemiological investigations on the spatial variations of diseases are often confined to 
using region-specific dummy variables to capture the spatial dimension. In this analysis, the regional patterns of childhood morbidity, and possible non-linear effects of other factors, were explored within a simultaneous, coherent regression framework, using a geo-additive, semi-parametric, mixed model. The fully Bayesian approach that was applied (Fahrmeir and Lang, 2001) is based on Markov priors and uses MCMC techniques for inference and model checking.

Consider regression situations, where observations $\left(y_{i} ; x_{i} ; w_{i}\right) ; i=1 ; \ldots ; N$, on a metrical response $y$, a vector $x=\left(x_{i} ; \ldots ; x_{p}\right)^{\prime}$ of metrical covariates (child's age), times scales or spatial covariates (states) and a vector $w=\left(w_{1} ; \ldots ; w_{r}\right)^{\prime}$ of further covariates, in which categorical covariates are often given. The generalized additive modelling framework assumes that, given $x_{i}$ and $w_{i}$, the distribution of the response $y_{i}$ belongs to an exponential family, with mean $\mu_{\mathrm{i}}=\left(y_{i} \mid x_{i}, w_{i}\right)$ linked to an additive semi-parametric predictor $\mu_{\mathrm{i}}=h(\eta)$.

Traditionally, the effect of the covariates on the response is modelled by a linear predictor:

$$
\eta_{i}=x_{i}^{\prime} \beta+w_{i}^{\prime} \gamma
$$

where $h$ is a known response function. The response variable in this application is defined as $y_{i}=1$ (if child $i$ had diarrhoea or cough or fever during the reference period $t$ ) or $y_{i}=0$ (if otherwise). There is a logit link function, $\operatorname{Pr}\left(y_{i}=1 \mid \eta_{i}\right)=\mathrm{e}^{\eta i} /\left(1+\mathrm{e}^{\eta i}\right)$, for the probability of having diarrhoea, cough, fever during the reference period (i.e. the conditional probability of a child having diarrhoea or cough or fever is modelled), given the child's age in months, the state where the child lives, and $w$, with predictor (Equation 1).

In the present application, and in many other regression situations, two problems have to be faced:

(1) for the continuous covariates in the data-set, the assumption of a strictly linear effect on the response $y$ may not be appropriate. In this study, such covariates are child's age and mother's age at birth of the child. Generally, it will be difficult to model the possibly non-linear effect of such covariates through a parametric functional form, which has to be linear in the parameters, prior to any data analysis.

(2) in addition to the usual covariates, geographical small-area information is given in the form of a location variable $s$, indicating the region, district, state or community where individuals or units in the sample live or originate. In the present study, this geographical information is given by the state where the child lived at the time of each survey. Attempts to include such small-area information using state-specific dummyvariables would entail $>50$ dummyvariables and could not be used to assess spatial inter-dependence. The latter problem could also not be solved through conventional multi-level modelling using uncorrelated random effects (Fahrmeir and Lang, 2001; Brezger et al., 2005). It is reasonable to assume that areas close to each other are more similar than areas far apart, so that spatially correlated random effects can be specified as shown in Equation 2.

To overcome these difficulties, the strictly linear predictor is replaced with a geoadditive predictor, leading to the geoadditive regression model:

$$
\begin{aligned}
\eta_{i}= & f_{1}\left(x_{i 1}\right)+\ldots+f_{p}\left(x_{i p}\right) \\
& +f_{\text {spat }}\left(s_{i}\right)+w_{i}^{\prime} \gamma
\end{aligned}
$$

where, $f_{1}, \ldots, f_{p}$ are non-linear smooth effects of the metrical covariates, and $f_{\text {spat }}\left(s_{i}\right)$ is the effect of the spatial covariate $s_{i}\{1, \ldots$, $S$ \} labelling the states in Nigeria.

In a Bayesian approach, the unknown functions $f_{j}$ and parameters $\gamma$ as well as the variance parameter $\sigma^{2}$ are considered as random variables and have to be supplemented with appropriate prior assumptions. 
In the absence of any prior knowledge, independent diffuse priors $\gamma_{j} \propto$ const, $j=1$, $\ldots, r$ were assumed for the parameters of fixed effects (another common choice is highly dispersed Gaussian priors).

Several alternatives (Fahrmeir and Lang, 2001; Brezger et al., 2005; Kandala, 2006) are available as smoothness priors for the unknown functions $f_{j}\left(x_{j}\right)$. In this study, Bayesian P(enalized)-splines (Brezger et al., 2005) were used. For the spatially correlated effect $f_{\text {str }}(s), s=1, \ldots, \mathrm{S}$, the Markov random field priors that are common in spatial statistics (Fahrmeir and Lang, 2001; Brezger et al., 2005; Kandala, 2006) were employed. These priors reflect spatial neighbourhood relationships. For a spatially uncorrelated (unstructured) effect $f_{\text {unstr }}$, a common assumption is that the parameters $f_{\text {unstr }}(s)$ are independent identically distributed Gaussian.

The standard measure of effect is still the OR for a logistic model. The use of a fully Bayesian approach that relies on prior assumption to make posterior inference means, however, that these ratios are 'posterior OR'. For model choice, the deviance information criterion (DIC) is routinely used as a measure of fit and model complexity, instead of tests for significance, linear trends and interactions. To account for possible departures from the assumed distribution, 95\% credible intervals for the posterior $\mathrm{OR}$ and probability maps are calculated using S.E. estimated via MCMC simulation techniques. 